\author{
Alessandro R. Rodrigues \\ roger@mat.feis.unesp.br \\ São Paulo State University - UNESP \\ Engineering Faculty of Iha Solteira \\ Av. Brasil Centro, 56 \\ 15385-000 llha Solteira, SP. Brazil \\ Reginaldo T. Coelho \\ rtcoelho@sc.usp.br \\ University of São Paulo - USP \\ Engineering School of São Carlos \\ Av. Trabalhador Sãocarlense, 400 \\ 13566-590 São Carlos, SP. Brazil
}

\section{Influence of the Tool Edge Geometry on Specific Cutting Energy at High- Speed Cutting}

This paper presents specific cutting energy measurements as a function of the cutting speed and tool cutting edge geometry. The experimental work was carried out on a vertical CNC machining center with 7,500 rpm spindle rotation and $7.5 \mathrm{~kW}$ power. Hardened steels ASTM H13 (50 HRC) were machined at conventional cutting speed and high-speed cutting (HSC). TiN coated carbides with seven different geometries of chip breaker were applied on dry tests. A special milling tool holder with only one cutting edge was developed and the machining forces needed to calculate the specific cutting energy were recorded using a piezoelectric 4-component dynamometer. Workpiece roughness and chip formation process were also evaluated. The results showed that the specific cutting energy decreased $15.5 \%$ when cutting speed was increased up to $700 \%$. An increase of $1{ }^{\circ}$ in tool chip breaker chamfer angle lead to a reduction in the specific cutting energy about $13.7 \%$ and $28.6 \%$ when machining at HSC and conventional cutting speed respectively. Furthermore the workpiece roughness values evaluated in all test conditions were very low, closer to those of typical grinding operations $(\sim 0.20 \mu \mathrm{m})$. Probable adiabatic shear occurred on chip segmentation at HSC.

Keywords: specific cutting energy, tool edge geometry, high-speed cutting

\section{Introduction}

Researches in machining processes have occupied a position of central importance in technological field nowadays. The significant economic impact of the machining processes represents approximately $15 \%$ of all manufactured products (Merchant, 1998). According to Trent (2000) the machining processes play a relevant role in transforming all metal production in workpieces as well as employ millions of people around the world. Therefore, the growing demand for research in this area represents great challenges for industries which always aim at productivity, quality, flexibility and compatibility to the environment.

The machining processes have evolved very fast lately. The improvement on coatings, substrates and tool edge geometries, CNC interfaces and machine tool performance, for instance, have allowed an increase in cutting speeds up to levels denominated High-Speed Cutting - HSC. Despite controversial opinions the main advantages attributed to HSC are high material removal rate, low cutting forces, good workpiece surface finish, high heat transfer, small workpiece distortions and low levels of vibrations during the cutting (Dewes and Aspinwall, 1997; Schulz et al., 2001; Tönshoff et al., 2001).

It can be noticed that the machining researches concerning tool geometry and specific cutting energy have been carried out since around 1950. However, most of these studies have been performed by adopting conventional cutting speeds and focusing traditional geometrical parameters of tools, such as rake, clearance, work cutting edge and cutting edge inclination angles. Considering HSC as a current machining concept, it is possible to note that the effect of recent tool geometries i.e. chip breaker and cutting edge shapes on specific cutting energy has not been widely investigated.

The specific cutting energy can be considered as an adequate parameter to study HSC. It can represent very well the cutting phenomenon, since it is normalized and is more sensitive to low depth of cut, condition specially applied in HSC operations. King and Hahn (1986) state that specific cutting energy can be understood as a ratio between cutting power and material removal rate, or an equivalent parameter between cutting energy and the volume of removed chip.
Results of cutting force and roughness commonly investigated using HSC have presented divergent tendencies, depending on the consulted source of scientific work. Klocke and Hoppe (2001) turning AISI 1045 steel and 7075 aluminum alloy with cutting speed from 250 to $6,000 \mathrm{~m} / \mathrm{min}$ verified that the cutting force decreased when $2,000 \mathrm{~m} / \mathrm{min}$ for steel and 3,000 $\mathrm{m} / \mathrm{min}$ for aluminum speeds were reached. After these limits the cutting forces increased.

Silva (2002) turning Inconel 718 alloy between 300 and $600 \mathrm{~m} / \mathrm{min}$ observed a constant cutting force with increase in cutting speed. Yousefi and Ichida (2000) investigated the influences of HSC techniques on workpiece roughness, chip formation mechanism and cutting forces when machined aluminum alloys. The researchers concluded that the workpiece roughness increased when cutting speed was increased. They proved that the formation of welded metal on tool minor cutting edge and the chip side flow were the cause in increase of roughness.

Despite some controversies HSC is still in great expansion not only at research centers but also in manufacturing industries. In addition, the main factor that limits the HSC evolution depends basically on tool developments, such as coatings, substrates and cutting edge geometries.

This paper aims mainly to measure the specific cutting energy under HSC condition and determine possible relationships between tool edge geometries and results of cutting force, surface roughness and chip formation mechanism.

\section{Nomenclature}

$\mathrm{A}=$ tool edge chamfer length, $\mathrm{mm}$

$\mathrm{a}_{\mathrm{p}}=$ depth of cut, $\mathrm{mm}$

$\mathrm{B}=$ tool edge chamfer angle, deg

$\mathrm{C}=$ chip breaker angle, deg

$\mathrm{f}=$ feed rate, $\mathrm{mm} / \mathrm{rev}$

$\mathrm{F}_{\mathrm{c}}=$ cutting force, $\mathrm{N}$

$\mathrm{F}_{\mathrm{x}}=\mathrm{x}$-axis dynamometer force, $\mathrm{N}$

$\mathrm{F}_{\mathrm{y}}=\mathrm{y}$-axis dynamometer force, $\mathrm{N}$

$\mathrm{HRC}=$ Rockwell hardness, $\mathrm{kgf} / \mathrm{mm}^{2}$

$\mathrm{R}_{\mathrm{a}}=$ centerline average roughness, $\mu \mathrm{m}$

$\mathrm{r}_{\varepsilon}=$ tool corner radius, $\mathrm{mm}$

$\mathrm{t}_{\mathrm{c}}=$ cutting time, $\mathrm{s}$

$\mathrm{TiN}=$ Titanium nitride

$\mathrm{u}=$ specific cutting energy, $\mathrm{J} / \mathrm{mm}^{3}$ 
$\mathrm{V}_{\mathrm{c}}=$ cutting speed, $\mathrm{m} / \mathrm{min}$

$\mathrm{V}_{\text {chip }}=$ chip volume, $\mathrm{mm}^{3}$

\section{Greek Symbols}

$\alpha_{\mathrm{o}}=$ tool orthogonal clearance angle, $\mathrm{deg}$

$\gamma_{\mathrm{o}}=$ tool orthogonal rake angle, deg

$\chi_{\mathrm{r}}=$ tool work cutting edge angle, deg

\section{Experimental Apparatus and Procedures}

The tests were carried out using a CNC machining center Romi model Discovery 560. An acquisition system with a piezoelectric 4-component dynamometer Kistler model 9272 was used in order to record the machining forces during the milling operation. A special milling tool holder with $85 \mathrm{~mm}$ diameter was developed so that only one cutting edge could cut the workpiece material, Fig. 1.

The quenched steel ASTM H13 (50 HRC) with prismatic geometry $17 \times 24 \times 32 \mathrm{~mm}$ was set on dynamometer through an appropriate device, Fig. 1. The setup kept the workpiece rigidly fixed on the dynamometer and assured repeatability in position when substituting specimens for different machining conditions. The $32 \mathrm{~mm}$ cutting width was maintained constant for all tests.

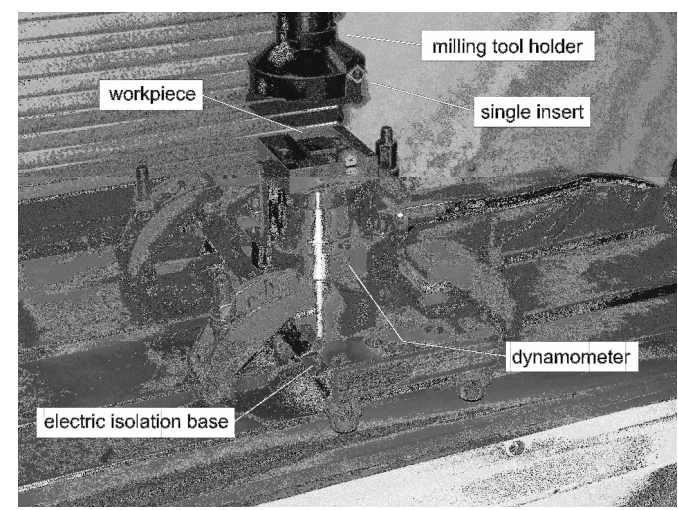

Figure 1. Experimental setup for measuring specific cutting energy in milling operation.

Seven different edge geometries of square carbide inserts were used on tests. All tools were provided by Sandvik Coromant Company. Geometrical details of chip breaker can be viewed in Fig. 2. The constant main features were $7^{\circ}$ orthogonal clearance angle $\left(\alpha_{o}\right), 7^{\circ}$ orthogonal rake angle $\left(\gamma_{\mathrm{o}}\right), 45^{\circ}$ work cutting edge angle $\left(\chi_{\mathrm{r}}\right)$, $0.8 \mathrm{~mm}$ corner radius $\left(\mathrm{r}_{\varepsilon}\right)$ and TiN coating.

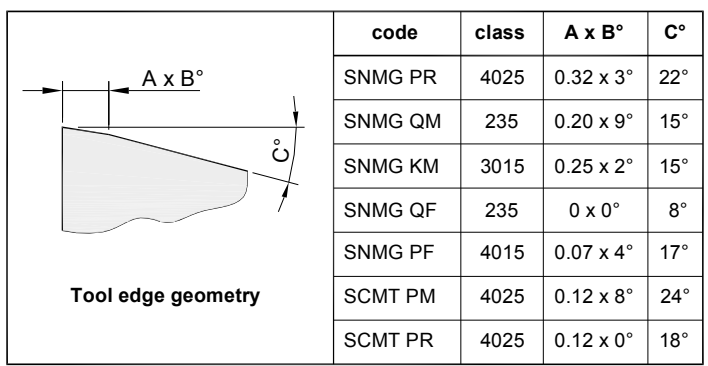

Figure 2. Chip breakers employed on milling tests. The denominations are: chamfer length (A), chamfer angle (B) and chip breaker angle (C).

The following cutting parameters were employed in dry machining tests for specific cutting energy measurements: $0.1 \mathrm{~mm}$ depth of cut, $8.0 \mathrm{~mm} / \mathrm{rev}$ feed rate, 50 and $400 \mathrm{~m} / \mathrm{min}$ cutting speeds. When face milling was employed to evaluate roughness, just feed rate and depth of cut were modified to $0.05 \mathrm{~mm} / \mathrm{rev}$ and $0.05 \mathrm{~mm}$ respectively.

The untypical feed rate was chosen for generating grooves spaced sufficiently from each other. The value was calculated considering the tool corner radius and depth of cut. This distance between two consecutive grooves was necessary so that plowing effect did not interfere in adjacent grooves. Despite high feed rate, pre-tests assured that inserts would not break during milling.

A new cutting edge was always used for each machining test to guarantee reliability on the results. All machining tests were carried out only once using the same methodology. The specific cutting energy was calculated by Eq. (1) using trapeze integration method, where $\mathbf{F}_{\mathbf{x}}$ and $\mathbf{F}_{\mathbf{y}}$ are vectorial force components, $\mathrm{v}_{\mathrm{c}}$ is cutting speed, $\mathrm{V}_{\text {chip }}$ is removed chip volume and $\mathrm{t}_{\mathrm{c}}$ is cutting time.

$$
u=\frac{v_{c}}{V_{\text {chip }}} \int_{0}^{t_{c}}\left(\boldsymbol{F}_{\boldsymbol{x}}{ }^{2}+\boldsymbol{F}_{\boldsymbol{y}}{ }^{2}\right)^{1 / 2} d t
$$

The removed chip volume was obtained by the difference in specimen mass (before and after testing) divided by material density whose value was determined considering the volume displacement method. The volume and mass measurements were performed at $20{ }^{\circ} \mathrm{C}$ (room temperature) with graduated cylinder of $250 \mathrm{ml}$ volume and precision scale BIOPRECISA model FA2104N with 0.0001 grams resolution respectively. All produced chips were examined in a scanning electron microscope (SEM) Zeiss model DSM 940A. The workpiece surface finish was evaluated using a roughness meter Rank Taylor Robson model Surtronic 3P with nose radius of $2 \mu \mathrm{m}$. The Center Line Average $\left(\mathrm{R}_{\mathrm{a}}\right)$ and cut-off of $0.8 \mathrm{~mm}$ were adopted in roughness measurements.

\section{Results and Discussions}

Figure 3 shows the specific cutting energy measurements related to the tool chip breaker geometries and two cutting speeds.

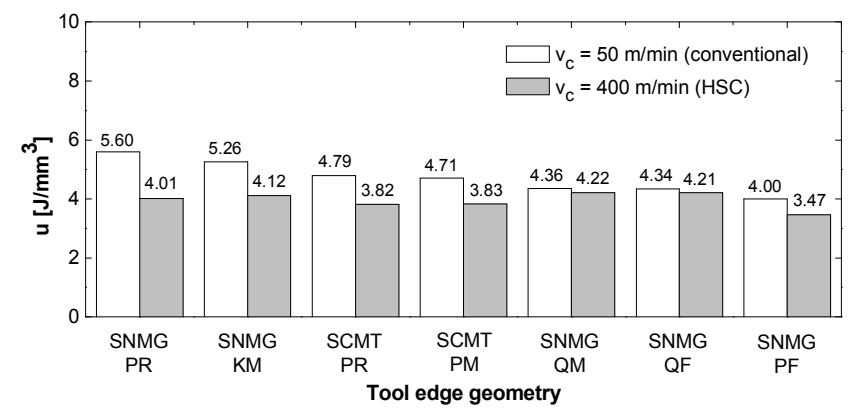

Figure 3. Influence of tool chip breaker geometry and cutting speed on specific cutting energy.

The results showed in Fig. 3 can be analyzed according to two criteria: tool chip breaker and cutting speed effects. In the first case, the specific cutting energy values tend to decrease with the easiness in chip formation process i.e. with increase in chamfer angle at a length equal or less than the depth of cut. The chip breaker angle, at lengths larger than the depth of cut also seems to play a role, being the second criterion to facilitate chip formation. Thus, the specific cutting energy demonstrates to depend on tool chip breaker geometry. Therefore, it is believed that this dependence is due to the combination between tool chip breaker geometry and depth of cut.

When analyzing the SNMG PR and SNMG PF tools in Fig. 3 it is noticed that the reduction of $0.25 \mathrm{~mm}$ in chamfer length and the increase of $1^{\circ}$ in chamfer angle caused the specific cutting energy to 
decrease about $28.6 \%$ and $13.7 \%$ for conventional cutting speed and high-speed cutting respectively.

The tools with intermediary specific cutting energy, such as SCMT PM, present edge geometry more favorable to cutting process than SNMG PR. In this case, the reduction of chamfer length and increase in $5^{\circ}$ of its angle provided a decrease nearly $16 \%$ on specific cutting energy. These results were evidenced mainly at conventional cutting speed (Rodrigues, 2005).

In particular, the SNMG QM and SNMG QF tools presented distinct results when submitted at high-speed cutting. These chip breakers interrupted the slight decrease tendency of specific cutting energy reaching a level $9.5 \%$ greater than mean value obtained by other tools. Even so, it is possible to assume that specific cutting energy demonstrates to be almost insensitive to cutting edge geometry at high-speed cutting. Figure 4 illustrates this verification graphically.

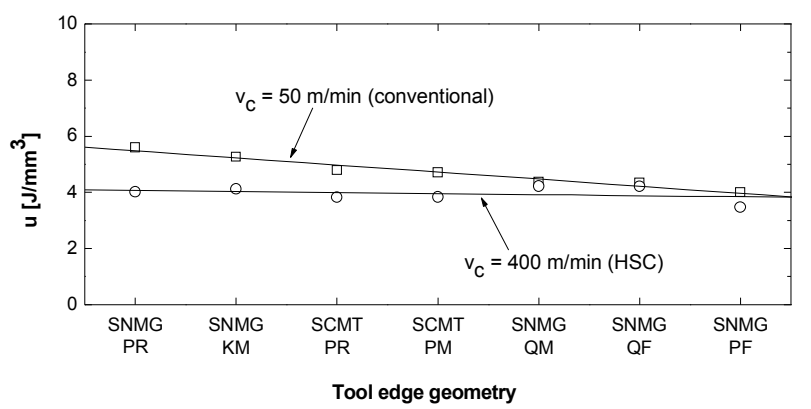

Figure 4. General tendency of the specific cutting energy due to tool chip breaker geometry and cutting speed.

Considering now the cutting speed in order to infer about specific cutting energy, it can be seen that specific cutting energy decreased $15.5 \%$ on average with increase in cutting speed from 50 to $400 \mathrm{~m} / \mathrm{min}$. In special the SNMG PR chip breaker reached a maximum reduction of $28.4 \%$. This result may have been caused by the decrease in chip-tool friction and increase in cutting zone temperature as well as in chip ratio (ratio between the uncut chip thickness and chip thickness). Besides, the chip-tool contact length must have decreased with increase in cutting speed and probably the formed chip was less sensitive to the action of chip breaker angle.

Additionally, chip segmentations were verified through scanning electron microscope (SEM) when carrying out high-speed cutting tests. This fact accounts for the reduction of cutting force amplitudes, as showed in Fig. 5. The values on the graph represent mean forces during the cutting time. The decrease in cutting force due to HSC condition was similar for all other tools.

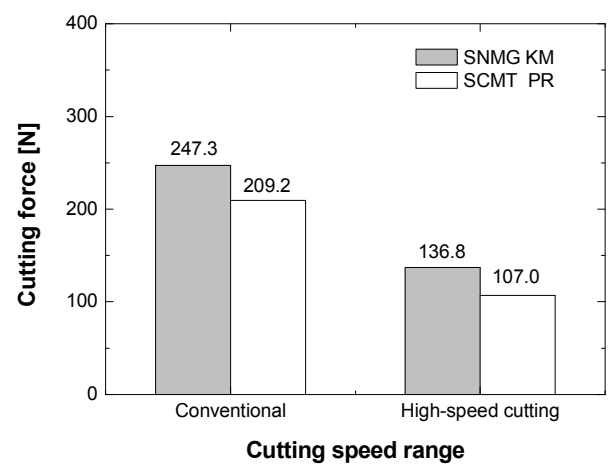

Figure 5. Influence of chip breaker and cutting speed on cutting forces generated when machining with SNMG KM and SCMT PR carbides.
Figure 5 demonstrates a significant reduction of cutting force (around 47\%) when going from conventional to HSC. If cutting power is calculated using the force graph and cutting speed, it can be seen for these two chip breakers that much more power is needed for HSC condition (increase of 326\%). This conclusion agrees with that presented by Diniz et al. (2000). According to the author the cutting power is more influenced by cutting speed at high speeds.

Figure 6 shows the results of workpiece roughness generated after HSC tests considering all the cutting tools.

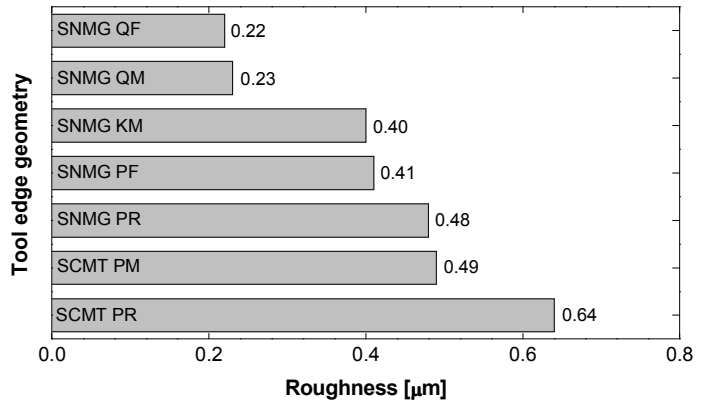

Figure 6. Influence of the tool chip breaker geometry on workpiece roughness at high-speed cutting.

In general it can be observed in Fig. 6 that higher roughness values were measured when machining with SCMT PR, SCMT PM and SNMG PR chip breakers. In these cases, some factors such as vibrations, machine-tool instability or difficulty in workpiece material strain may have influenced chip formation (Boehs, Steidel and Friedrich, 2001; Milan, 1999; Stipkovic Filho, Batalha and Faccio, 2005).

The SNMG PF and SNMG KM tools presented intermediate roughness values, 0.41 and $0.40 \mu \mathrm{m}$ respectively. In these cases, the influence of tool edge geometry could be evaluated because there was not tool coating degeneration. It is believed that the chamfer angle was responsible for decreasing in workpiece roughness, due to the low depth of cut adopted. The chip formation mechanism was probably improved.

The SNMG QF and SNMG QM tools outperformed others in terms of workpiece roughness. These values were reduced about $65 \%$ when compared to the highest surface roughness $(0.64 \mu \mathrm{m})$. The workpiece surface finish using these tools was improved probably due to the easiness in material shear and chip formation promoted by the highest chamfer angles $\left(8\right.$ and $\left.9^{\circ}\right)$.

As a final analysis related to roughness, an indicative of correlation was observed between specific cutting energy and surface finish. These variables revealed opposite behavior at high-speed cutting i.e. the lower surface roughness, the higher specific cutting energy, Fig. 7.

At first these variables should have the same tendency once less energy for chip formation would favor the roughness. A more detailed investigation permitted to conclude that the specific cutting energy was more dependent of chip breaker angle while the roughness was governed by chamfer angle. 


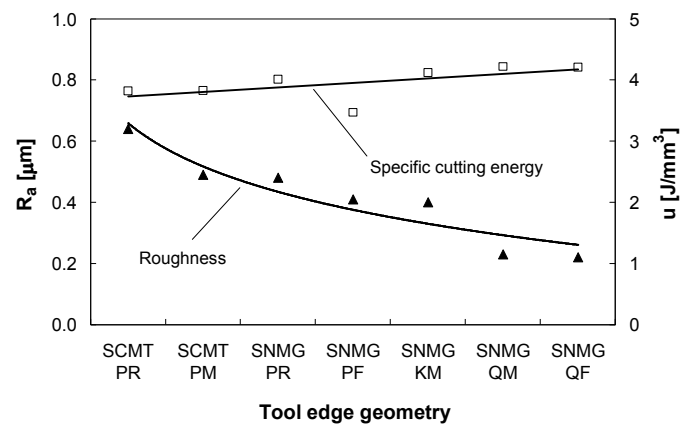

Figure 7. Behavior of specific cutting energy and workpiece roughness.

Considering a further comparison it is fully possible to associate the measured roughness values to those of grinding process. According to Ferraresi (1977), the workpiece roughness measurements $\left(R_{a}\right)$ for milling processes lie in $0.8-6.3 \mu \mathrm{m}$ range. These values are diminished to $0.2-3.2 \mu \mathrm{m}$ for grinding processes. The great advantage in using defined tool geometry bases on controlling its edge geometry. Thus, typical workpiece roughness from grinding processes could be reached by this research work.

Figure 8 concludes this result discussion by showing two samples of chips removed during the tests performed under conventional cutting speed and high-speed cutting.
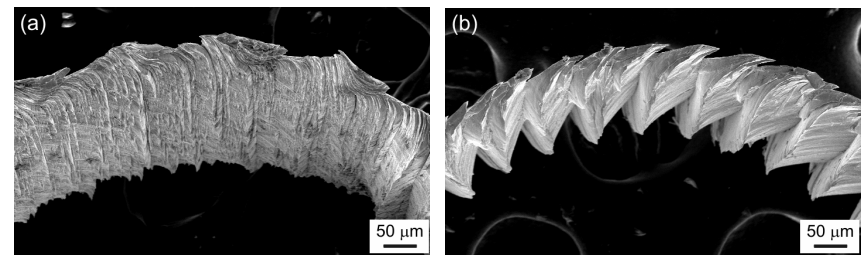

Figure 8. Hardened chip samples obtained at (a) conventional cutting speed and (b) HSC.

The images presented above represent the central focus of this chip visual characterization. They illustrate that the chip formation process composed by both elastic and plastic strain was probably modified due to cutting speed variation. It is relevant to mention that visual analyses of tool rake face were done for each tested insert and built-up edge occurrences were not verified. In spite of employing on trials low cutting speed $(50 \mathrm{~m} / \mathrm{min})$ the built-up edge was not formed likely due to low ductility of machined material. The built-up edge could have influenced on formation of chips and modified both their morphology and microstructure (Shaw, 2004).

Figure 8a shows a chip portion where the continuity of lamellas is clearly visible, although there is a saw-tooth shape very reduced. However, Fig. 8b illustrates more evidently an accentuated chip segmentation level, including regions of nucleation, growth and arrest of cracks on the chip top surface. They may have been generated by slight chip curvature when machined at high strain rate associated to the low workpiece material plasticity. These chip samples were obtained with all cutting parameters maintained constant including the tool edge geometry.

At first the segmented chip presented in Fig. $8 \mathrm{~b}$ may have been produced due to adiabatic shear process since its morphology and dynamics of formation were governed by high-speed cutting applied in machining of hardened material. Meantime, this classification can be only confirmed by metallographic examinations of chip which must present intense deformation between the lamellas.

Segmented chips generated by adiabatic shear present intense concentrated shear bands and they are formed above a certain speed, such as high-speed cutting. High resistance alloys and hardened materials with low thermal properties cause either catastrophic or thermoplastic shear, where the ductility effect generated by increase in temperature overcomes the hardening effect of material originated due to high strain rates.

Finally, other relevant aspect to approach refers to the definition which literature uses to define the range between conventional cutting speed and high-speed cutting. In general, this distinction bases on specification of certain cutting speed values, because it is a criterion more feasible technologically. However, the cutting speed of $400 \mathrm{~m} / \mathrm{min}$ assumed as high-speed cutting in this work was an apparently correct chosen since it caused modifications in chip formation mechanism.

\section{Conclusions}

The following final conclusions are summarized bellow:

The tool chip breaker geometry causes influence on specific cutting energy behavior. Even small modifications on cutting edge geometry affect the cutting force levels and specific cutting energy values;

It is more evident the effect of cutting edge geometry on specific cutting energy at conventional cutting speed than at high-speed cutting. The reduction of $0.25 \mathrm{~mm}$ in chamfer length and increase of $1^{\circ}$ in chamfer angle (from SNMG PR to SNMG PF tools) caused a reduction on specific cutting energy nearly $28.6 \%$ and $13.7 \%$ for conventional cutting speed and high-speed cutting respectively;

The tests carried out at high-speed cutting provided cutting forces significantly lower than those obtained at conventional cutting speed condition. The SNMG KM and SCMT PR tools reduced the force levels about $47 \%$;

There was an indication of correlation between workpiece surface finish and specific cutting energy for HSC condition. In general, the higher the specific cutting energy, the lower the workpiece roughness. The tool edge chamfer angle and chip breaker angle caused distinct influences on this behavior probably;

The highest workpiece roughness measured was $0.64 \mu \mathrm{m}$ using SCMT PR chip breaker and the lowest value was $0.22 \mu \mathrm{m}$ for SNMG QF tool;

The chip formation mechanism could be classified into continuous chip for lowest cutting speed and segmented chip for highest cutting speed.

\section{Acknowledgments}

The authors are grateful to the State of São Paulo Research Foundation (FAPESP) by financial support and to the Laboratory for Optimization of Manufacturing Processes (OPF) at the Engineering School of São Carlos (EESC-USP).

\section{References}

Boehs, L., Steidel, P.S. and Friedrich, D., 2001, "Influência dos Parâmetros de Usinagem e da Geometria da Ferramenta sobre a Rugosidade Cinemática e de Processo" (In Portuguese), Proceedings of the $16^{\text {th }}$ Brazilian Congress of Mechanical Engineering, Vol.1, Uberlândia, MG, Brazil, pp. 467-476.

Dewes, R.C. \& Aspinwall, D.K., 1997, “A Review of Ultra High Speed Milling of Hardened Steels", Journal of Materials Processing Technology, No. 69, pp. 1-17.

Diniz, A.E., Marcondes, F.C. and Coppini, N.L., 2000, "Tecnologia da Usinagem dos Materiais", Ed. Artliber, São Paulo, Brazil, 244 p.

Ferraresi, D., 1977, "Fundamentos da Usinagem dos Metais", Ed. Edgard Blücher, São Paulo, Brazil, 751 p.

King, R.I. \& Hahn, R.S., 1986, "Handbook of Modern Grinding Technology", Ed. Chapman and Hall, USA, 360 p.

Klocke, F. \& Hoppe, S., 2001, "Mechanisms of Chip Formation in High Speed Cutting", In: Schulz, H. (Editor), "Scientific Fundamentals of HSC", Ed. Druckhaus, Munich, Germany, pp.1-10. 
Merchant, M.E., 1998, "An Interpretive Look at the 20th Century Research on Modeling of Machining", Machining Science and Technology, Vol. 2, pp. 157-163.

Milan, J.C.G., 1999, "Usinabilidade de Aços para Moldes para Plásticos" (In Portuguese), M.Sc. Dissertation, Federal University of Uberlândia (UFU), Uberlândia, MG, Brazil, 99 p.

Rodrigues, A.R., 2005, "Estudo da Geometria de Arestas de Corte Aplicadas em Usinagem com Alta Velocidade de Corte" (In Portuguese), Ph.D. Thesis, Engineering School of São Carlos, University of São Paulo, São Carlos, SP, Brazil, 227 p.

Schulz, H. et al., 2001, "High-Speed Machining - Fundamentals and Industrial Application", Proceedings of $6^{\text {th }}$ International Seminary of the High Technology - Advanced Manufacture, Piracicaba, SP, Brazil, pp. 25-44.

Shaw, M.C., 2004, "Metal Cutting Principles", Ed. Oxford University, England, $651 \mathrm{p}$.
Silva, L.R., 2002, "Estudo da Geometria da Aresta de Corte de Ferramentas Aplicadas ao Torneamento de Superligas à Base de Níquel com Alta Velocidade de Corte" (In Portuguese), Ph.D. Thesis, Engineering School of São Carlos, University of São Paulo, São Carlos, SP, Brazil, 211 p. Stipkovic Filho, M., Batalha, G.F. and Faccio, I., 2005, "Acabamento Superficial a Altíssima Velocidade de Corte" (In Portuguese), Máquinas e Metais, No. 468, pp. 142-153.

Tönshoff, H.K. et al., 2001, "High-Speed or High-Performance Cutting A Comparison of New Machining Technologies", Production Engineering, Vol. 8, No. 1, pp. 5-8.

Trent, E.M. \& Wright, P.K., 2000, "Metal Cutting”, Ed. Butterworth Heinemann, Boston, USA, 446 p.

Yousefi, R. \& Ichida, Y., 2000, "A Study on Ultra-High-Speed Cutting of Aluminum Alloy: Formation of Welded Metal on the Secondary Cutting Edge of the Tool and Its Effects on the Quality of Finished Surface", Precision Engineering, Vol. 24, pp. 371-376. 